\title{
Evaluation of ABL parametrization schemes in the COSMO, a regional non-hydrostatic atmospheric model over an inhomogeneous environment
}

\author{
T. J. Anurose ${ }^{1}$ D. Bala Subrahamanyam ${ }^{1}$
}

Received: 15 October 2015/Accepted: 31 October 2015/Published online: 18 November 2015

(C) Springer International Publishing Switzerland 2015

\begin{abstract}
The boundary-layer processes characterized through turbulent motion are generally very small scale and sub grid and are represented through different parametrization schemes in the atmospheric models. Here, we evaluate the performance of the atmospheric boundary layer (ABL) parametrization schemes in the COnsortium for Small-scale MOdelling (COSMO), a non-hydrostatic atmospheric model by comparing the model simulations with the concurrent in situ observations over Thiruvananthapuram $\left(8.5^{\circ} \mathrm{N}, 76.9^{\circ} \mathrm{E}\right.$, India). With a view to investigating the role of master length scale $(l)$ in simulation of the ABL features, the default parametrization scheme based on the 1-D diagnostic closure, is modified by adopting a new mathematical formulation for $l$, and the new approach is implemented in the COSMO model. A total of three parametrization approaches, including the two in-built schemes, are designed and the model simulations with these three distinct schemes are carried out for a total of 9 days. Results obtained from the present study reveal the role of $l$ in the estimation of eddy diffusivity coefficients $\left(K_{m}\right.$ and $\left.K_{h}\right)$ and the associated vertical turbulent mixing. The study also attempts to highlight the significance of ABL parametrization schemes over nonhomogeneous environment, hitherto least explored.
\end{abstract}

D. Bala Subrahamanyam

subrahamanyam@gmail.com

T. J. Anurose

anurostj@gmail.com

1 Space Physics Laboratory, Vikram Sarabhai Space Centre, Department of Space, Government of India, Indian Space Research Organization,

Thiruvananthapuram 695 022, Kerala, India
Keywords Atmospheric boundary layer - COSMO model · Eddy diffusivity coefficients · Master length scale . Turbulence parametrization

\section{Introduction}

The atmospheric boundary layer (ABL), extending upward from the Earth's surface, is substantially influenced by energy and moisture from the underlying surface through turbulent transport processes. The depth of the ABL produced by this turbulent transport mechanism undergoes prominent diurnal evolution over a land surface and may range from as little as $30 \mathrm{~m}$ in conditions of large static stability to more than $3 \mathrm{~km}$ in highly convective conditions (Arya 2001; Holton 2004). The boundary-layer processes in this layer regulate the fluxes of energy, momentum, and matter between the atmosphere and land or sea over a range of scales, varying from local to global. These processes can be characterized as complex physical and dynamical interactions dominated by turbulent transport and mixing. The turbulent motion responsible for this interaction is generally very small scale and totally sub grid and therefore needs to be parametrized in numerical weather prediction (NWP) models (Deardorff 1972; Troen and Mahrt 1986; Pielke 2002; Teixeira et al. 2003; Lee and Hong 2005). The basic role of an ABL parametrization scheme is to provide the coupling with the surface through the determination of turbulent fluxes and their vertical diffusion, to give realistic forecasts of near surface parameters such as temperature, specific humidity and wind and to provide input to the cloud and convection schemes (Pielke 2002; Teixeira et al. 2003). With the development of highresolution atmospheric models used for the NWP, requirements for accurate $\mathrm{ABL}$ parametrization schemes 
have dramatically increased, making them a key element in the weather and climate predictions, as well as in several other environmental applications, such as pollutant dispersion and biometeorology (Yamartino and Wiegand 1986; Nielsen-Gammon et al. 2010; $\mathrm{Hu}$ et al. 2010). Despite a considerable progress in the prediction of synoptic weather conditions through atmospheric models, the errors and uncertainties associated with the ABL parametrization schemes in the NWP model simulations remain one of the primary sources of inaccuracies, especially for the tropics where small-scale cumulus convection dominate (Basu et al. 1998, 1999; Lee and Hong 2005; Pleim 2007a, b; Shah et al. 2010). One of the major challenges of modelling the ABL processes through parametrization is the prediction of the temporal variation of vertical and horizontal structures in response to the influence of the major processes acting in the atmosphere and at the Earth's surface.

A satisfactory performance of the ABL parametrization scheme in an NWP model is critical for proper prediction of the diurnal cycle, low-level winds and convergence, effects of complex terrain, and timing and location of convection. Further, the role of an ABL parametrization scheme becomes more challenging when the surface inhomogeneities such as boundaries between land and water surfaces (coastline), different types of vegetation, and hills and valleys influence the atmospheric flow (Arya 2001). In such situations, the terrain is effectively characterized with surface inhomogeneities and the ABL itself behaves in an non-homogeneous fashion over such locations. The parametrization of nonhomogeneous ABL processes in the NWP models are not widely addressed and require proper attention. In this regard, we present a detailed evaluation on the performance of $\mathrm{ABL}$ parametrization schemes in a regional non-hydrostatic atmospheric model, namely-COnsortium for Small-scale MOdelling (COSMO), for a coastal domain centred around Thiruvananthapuram $\left(8.5^{\circ} \mathrm{N}\right.$, $76.9^{\circ} \mathrm{E}$, India), where the $\mathrm{ABL}$ processes are mostly non-homogeneous in nature and are affected through mesoscale sea-breeze circulation (Anurose et al. 2012). The main objective of the present research work is to assess the performance of three distinct approaches of the ABL parametrization in the COSMO model by comparing the boundary-layer features in terms of the vertical profiles of mean meteorological parameters, the ABL heights, and their diurnal variations obtained from the model simulations with the concurrent observations. The study also examines the role of master length scale in the estimation of eddy diffusivity coefficients, and its impact on the predictions of mean meteorological parameters in the lower atmosphere.

\section{Details of COSMO model and numerical experiments}

The COSMO (formerly known as "Lokal-Modell" in Germany or "Alpine Model" in Switzerland), a non-hydrostatic limited area atmospheric prediction model was initially developed at Deutscher Wetterdienst (German Weather Services) for operational NWP and various research applications on the meso- $\beta$ and meso- $\gamma$ scale and later in the framework of the COSMO consortium (Steppeler et al. 2003; Buzzi 2008; Baldauf et al. 2011). The three-dimensional fully elastic and non-hydrostatic atmospheric equations in this model are based on the primitive thermo-hydrodynamical equations and are solved numerically with second- or third-order finite difference methods on a Arakawa-C grid system. The lowest level of the model is placed in $10 \mathrm{~m}$ above the ground and a generalized terrain following height coordinate system is adopted for the definition of vertical grid points (Schar et al. 2002). The prognostic variables include horizontal and vertical Cartesian wind components, pressure perturbation, temperature, specific humidity, cloud water content, cloud ice content, turbulent kinetic energy (TKE), specific water content of rain, snow and graupel, whereas the total air density, precipitation fluxes of rain and snow are treated as diagnostic variables.

\section{Parametrization of ABL processes in COSMO}

The turbulence length scales vary typically from a few millimetres to a few hundreds of metres, which are smaller than the grid spacing of the atmospheric models, hence a mathematical framework for the representation of such sub grid processes in NWP models is accomplished through parametrization. As the scale of turbulence in ABL is broadly classified into two categories consisting quasi-local small eddies and the non-local large eddies, two separate approaches are being followed in the parametrization of ABL processes (Stensrud 2007), viz;

1. In the first approach (i.e., bulk/slab or mixed layer model), a well-mixed boundary layer is described through the evolution of ABL by its depth, its mixed layer values and the jump in these conserved variables at the top of the ABL. Though these models are very simple and realistic, and do not rely on high vertical resolution, they are difficult to implement in a large scale model as it involves a moving lower boundary. Furthermore, these mixed layer models do not handle the stable boundary layer quite effectively where the quantities are not so well mixed. 
2. The second approach (i.e., eddy diffusivity or $K$ closure) largely rely on the determination of the eddy diffusivity coefficients for heat $\left(K_{h}\right)$ and momentum $\left(K_{m}\right)$ in terms of the grid-scale variables and the ABL processes are explicitly resolved. In this approach, the effect of small eddies are parametrized following the Monin-Obukhov similarity in analogy with the molecular diffusion, and the vertical fluxes are assumed to be proportional to the mean vertical gradients.

The COSMO model offers two different approaches based on the $K$-closure for the parametrization of ABL processes. The first approach, the 1-D diagnostic closure (hereafter referred to as $M Y_{D}$ scheme), makes use of boundary-layer approximation by imposing horizontal homogeneity of variables and fluxes resulting in a neglection of all horizontal turbulent fluxes. This approximation is applicable when the horizontal scales of motion are much larger than the vertical scale (Doms 2011). The second approach, namely the 1-D TKE based diagnostic closure (hereafter referred to as $M Y_{T K E}$ scheme), is formulated on conservative thermodynamic variables together with a statistical cloud scheme following Someria and Deardoff (1976) in order to incorporate subgrid-scale condensation effects on the eddy diffusivity coefficients. The basic differences in these two ABL schemes are shown through a flow chart in Fig. 1. In the $M Y_{D}$ scheme, the mathematical formulation for the estimation of eddy diffusivity coefficients is derived from a diagnostic equation for the TKE based on Mellor and Yamada (1974) second-order closure scheme. As per this scheme, $K_{m}$ and $K_{h}$ are treated as functions of vertical wind shear, stability of the atmosphere in terms of Richardson number $\left(R_{f}\right)$, and a master length scale $(l)$. This master length scale is often defined as the maximum length that an eddy can move vertically during the process of turbulent mixing with the surroundings, and therefore broadly represents the maximum possible size of an eddy. The basic meteorological variables, such as zonal $(u)$ and meridional $(v)$ winds, together with the potential temperature $(\theta)$ are used for the determination of vertical wind shear $(M)$ and Brunt-Vaisala frequency $(N)$ for different altitude $(z)$ levels, which are later used for the estimation of $R_{f}$. The atmospheric stability is then expressed in terms of the stability functions for heat $\left(S_{h}\right)$ and momentum $\left(S_{m}\right)$. The final yield of eddy diffusivity coefficients through the $M Y_{D}$ scheme is given as:

$$
\begin{aligned}
& K_{m}=l^{2} \cdot S_{m}^{3 / 2} \cdot \sqrt{\left(M^{2}-\alpha_{n} \cdot S_{h} \cdot N^{2}\right)} . \\
& K_{h}=\alpha_{n} \cdot S_{h} \cdot K_{m} .
\end{aligned}
$$

where the constant parameter $\alpha_{n}(=1)$ denotes the ratio of diffusion coefficient for heat and momentum at neutral stratification. This diagnostic form reveals an equilibrium between the dissipation of turbulent kinetic energy and its production due to mechanical forcing by wind shear and thermal forcing by buoyancy. The $M Y_{D}$ scheme, however does not account for the condensation and evaporation of cloud water and its impact on the eddy diffusivity coefficients. On the other hand, the $M Y_{T K E}$ scheme accounts for the sub grid scale condensation effects by utilizing the additional conservative thermodynamic variables, such as liquid water potential temperature $\left(\theta_{l}\right)$, and total water $\left(q_{w}\right.$ $=q_{v}+q_{c}$ ) in terms of vapour and cloud respectively, as shown in Fig. 1. Here the stability functions for heat and momentum appear to be the solutions of two linear equations which contain the vertical wind shear $(M)$ and buoyancy forcing (through $\theta, \theta_{l}, q_{v}$ and $q_{c}$, as indicated in Fig. 1) (Baldauf et al. 2011). Finally, the eddy diffusivity coefficients for heat and momentum in the $M Y_{T K E}$ scheme are derived as per the following equations:

$$
\begin{aligned}
& K_{m}=q . l . S_{m} . \\
& K_{h}=q . l . S_{h} .
\end{aligned}
$$

In the above two equations, the turbulent velocity scale $(q=\sqrt{2 T K E})$ is predicted through a prognostic TKE equation comprising the turbulent production, transport and dissipation. This scheme also includes the transition of large scale diffusive turbulence to very small scale dissipative turbulence by the action of small scale roughness elements, and thereby handles the non local vertical diffusion (Raupach and Thom 1981). In both these schemes, the master length scale is estimated using the following equation, as proposed by Blackadar (1962):

$$
l=\frac{\kappa \cdot z}{1+\frac{\kappa \cdot z}{l_{\infty}}} \text {. }
$$

In the Blackadar (1962) approach, $l$ is defined as a combination of the Prandtl mixing length with a limiting value close to the surface and a length scale depending on the TKE distribution in the vertical column of the boundary layer as a limiting value towards the top of the boundary layer. Through the above equation, it is assumed that the $l$ varies as $\kappa . z$ close to the surface (where $\kappa$ is von Karman constant) and attains a constant value of $l_{\infty}$ at greater heights, which prevents the turbulent length scale from growing infinitely above the surface. In the COSMO model, the asymptotic length scale $\left(l_{\infty}\right)$ is assigned a constant value of $500 \mathrm{~m}$.

\section{Modification to the master length scale}

In both the ABL schemes of the COSMO model described in the previous section, the master length scale, a mathematical representative of the whole turbulent spectrum, is treated as a function of height alone. However, such a 
Fig. 1 A schematic flowchart representing the mathematical formulations adopted for the estimation of eddy diffusivity coefficients of momentum and heat $\left(K_{m}\right.$ and $K_{h}$ ) for two default $\mathrm{ABL}$ parametrization schemes, viz; (i) $M Y_{D}(1-\mathrm{D}$ diagnostic closure) and (ii) $M Y_{T K E}$ (1-D TKE based diagnostic closure) respectively in the COSMO model

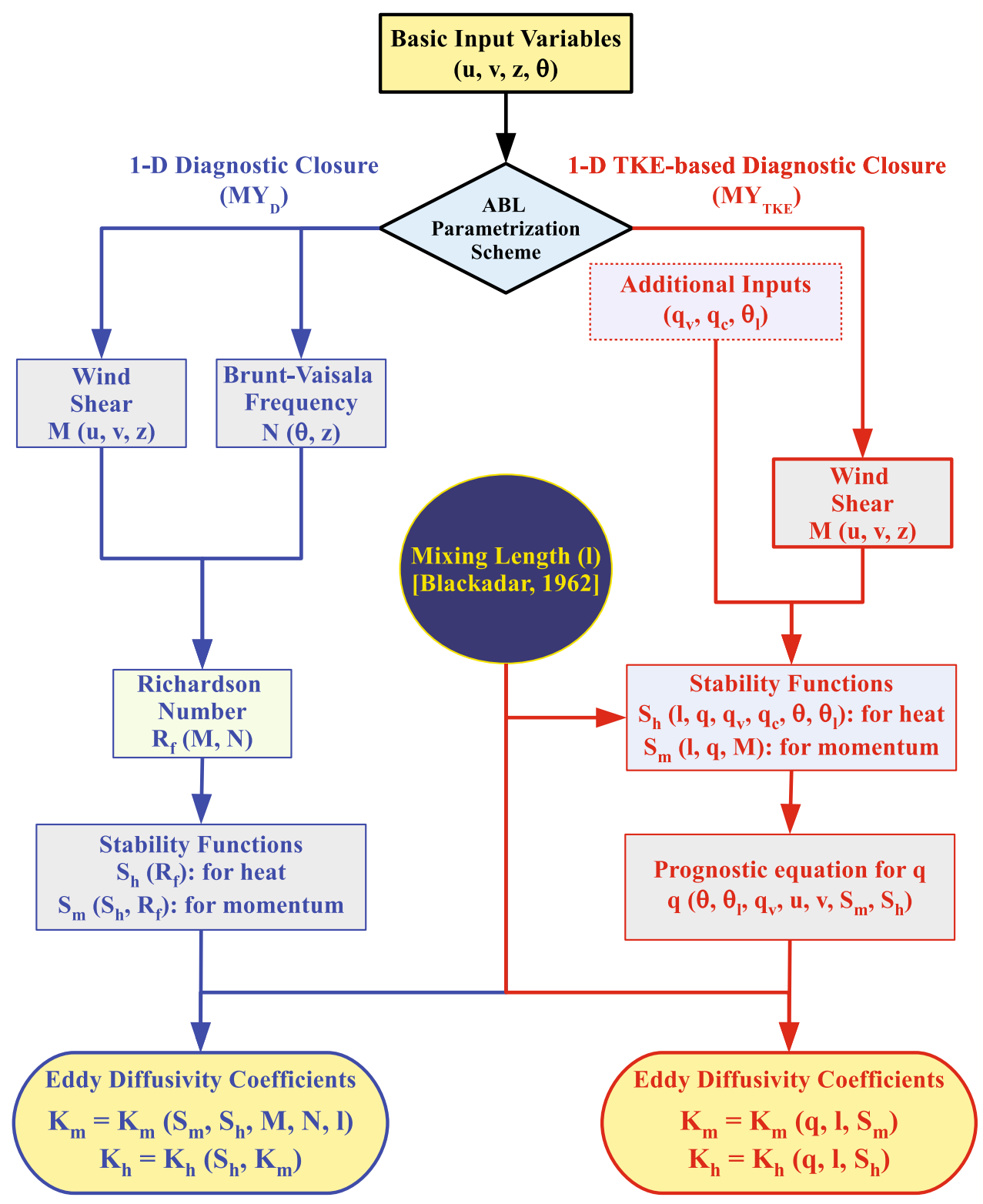

representation of $l$ lacks in adequate information on the stability conditions of the atmosphere (Nakanishi 2001; Teixeira and Cheinet 2004; Suelj and Sood 2010). It is known that for extremely unstable and stable stratification of the atmosphere, the rate of turbulent mixing and associated diffusion behave in a different fashion. In such situations, the mathematical formulation of $l$ must ideally include the stability effects, so as to represent the vertical mixing and diffusion processes within the $\mathrm{ABL}$ in an appropriate manner. Several studies in the past have proposed different kind of formulations for $l$, leading to more realistic representation of turbulent fluxes and mean vertical profiles (Lenderink and Holtslag 2004; Teixeira and Cheinet 2004). Based on the large eddy simulation data,
Nakanishi (2001) addressed the deficiency in the expression for the $l$ in Mellor and Yamada (1974) scheme through a new diagnostic equation by allowing variations in the $l$ with stability. In the present study, we have altered the $M Y_{D}$ scheme for accounting the stability corrections in the master length scale by incorporating a new diagnostic equation for $l$ based on Nakanishi (2001). Thus, in the new diagnostic closure approach (hereafter referred to as $M Y_{\text {lnew }}$ ), the mathematical formulation is exactly same as that of the $M Y_{D}$ scheme, except for an alteration in the definition of the $l$. Instead of treating the master length scale merely as a function of altitude, it is taken to be dependent on three different length scales as per the following equation (Nakanishi 2001; Suelj and Sood 2010): 
$\frac{1}{l}=\frac{1}{l_{s}}+\frac{1}{l_{b}}+\frac{1}{l_{\infty}}$.

where $l_{s}, l_{b}$ and $l_{\infty}$ represent the surface length scale, buoyancy suppression length scale and an asymptotic length scale respectively. Within the surface layer, the magnitudes of $l_{s}$ are defined in a such a way that the master length scale is constrained from growing infinitely close to the surface. The second term $l_{b}$ is mainly used to suppress the magnitudes of master length scale for statically stable atmosphere, especially in the upper part of the boundary layer. The $l_{\infty}$ in the above expression is same as that in the $M Y_{D}$ scheme.

The $l_{s}$ and $l_{b}$ are assumed to be stability dependent and vary in accordance with the following equations for stable, neutral and unstable cases:

$$
\begin{array}{rr}
\kappa . z .(1+2.7 \zeta)^{-1}, & \zeta>0 \\
l_{s}=\kappa . z, & \zeta=0 \\
\kappa . z .(1-100 . \zeta)^{0.2}, & \zeta<0
\end{array}
$$

whereas, $l_{b}$ is expressed as:

$$
\begin{aligned}
& \alpha 2 . q / N, \quad \frac{\partial \theta_{v}}{\partial z}>0 ; \quad \zeta \geq 0 \\
& l_{b}=\left(\alpha 2 . q+\alpha 3 . q \cdot \sqrt{\frac{q_{0}}{l_{\infty}} . N}\right) / N, \quad \frac{\partial \theta_{v}}{\partial z}>0 ; \quad \zeta<0 \\
& \infty, \quad \frac{\partial \theta_{v}}{\partial z} \leq 0
\end{aligned}
$$

In the above two expressions, $\zeta$ represents the surface-layer stability parameter, whereas two variables $\alpha 2$ and $\alpha 3$ are assigned to constant values of 1 and 5 respectively based on large eddy simulation data (Nakanishi 2001; Suelj and Sood 2010). The term $q_{0}$ is a vertical velocity scale and is defined as:

$q_{0}=\left(\frac{g}{\theta_{v s}} \cdot \overline{w^{\prime} \theta_{v}^{\prime} \|_{s}} l_{\infty}\right)^{1 / 3}$,

The subscripts 's' associated with different parameters in the above equations are representative of the surface values.

\section{Numerical experiments in the COSMO model}

With a goal of evaluating the performance of $\mathrm{ABL}$ parametrization schemes in the COSMO model, three distinct numerical experiments, each one with a unique approach, are carried out and the vertical profiles of simulated parameters are compared with the in situ observations over Thiruvananthapuram. Two numerical experiments, namely (i) $M Y_{D}$ and (ii) $M Y_{T K E}$ corresponding to the 1-D diagnostic closure and 1-D TKE based diagnostic closure approaches of the ABL parametrization scheme respectively are based on the default configurations available in the COSMO model. In addition to these experiments, we have designed a new parametrization approach, namely (iii) $M Y_{\text {lnew }}$, in which the role of master length scale in non-homogeneous conditions of the ABL is evaluated with a stability dependent definition of $l$ following the mathematical formulation of Nakanishi (2001). In all these numerical experiments, the ABL parametrization approaches are kept distinct, whereas the rest of the model physics and numerical techniques remain identical to each other. Table 1 provides brief summary of the technical details of the COSMO, together with the model configuration used in the present study. The initial conditions for all these simulations are extracted from the analyses of GME, a German global model, corresponding to 0000 UTC, whereas the lateral boundary conditions are derived from the forecast fields of GME at +3 hourly intervals. The vertical profiles of different meteorological parameters obtained from balloon-borne platform form the primary in situ database. Technical details on the functioning of balloon-borne GPS sondes used in the present study, sensor accuracies and method of analysis are described elsewhere (Subrahamanyam et al. 2012). A total of 72 GPS sondes were launched from Thiruvananthapuram at +3 hourly intervals for three consecutive days in February 2011, 2012 and 2013 respectively, when the experimental site witnessed relatively clear-sky weather conditions. For these 9 days, the COSMO model simulations are carried out by generating $+24 \mathrm{~h}$ forecast with three distinct $\mathrm{ABL}$ parametrization schemes.

\section{Results and discussions}

The present study is carried out over Thiruvananthapuram, one of the southern coastal stations in the Indian subcontinent (Fig. 2). The model domain chosen for this study is mostly heterogeneous in nature with uneven terrain/plantations surrounding the western ghats on one side of Thiruvananthapuram and the Arabian sea on the other side. A steep topography on the eastern side of Thiruvananthapuram in conjunction with the Arabian sea on the western sector make the boundary-layer dynamics very interesting over the experimental site. The vertical structure of the ABL over this site is effectively influenced by inhomogeneity in the surface-layer features of the underlying terrain, and is also modulated through the presence of diurnal evolution of meso scale sea-breeze circulation, thereby providing a natural laboratory for the evaluation of ABL parametrization schemes under non-homogeneous conditions. The spatial heterogeneity over this domain in terms of the roughness length and terrain elevation is depicted through shaded area and contour lines 
Table 1 Technical description of the COSMO model used in the present study

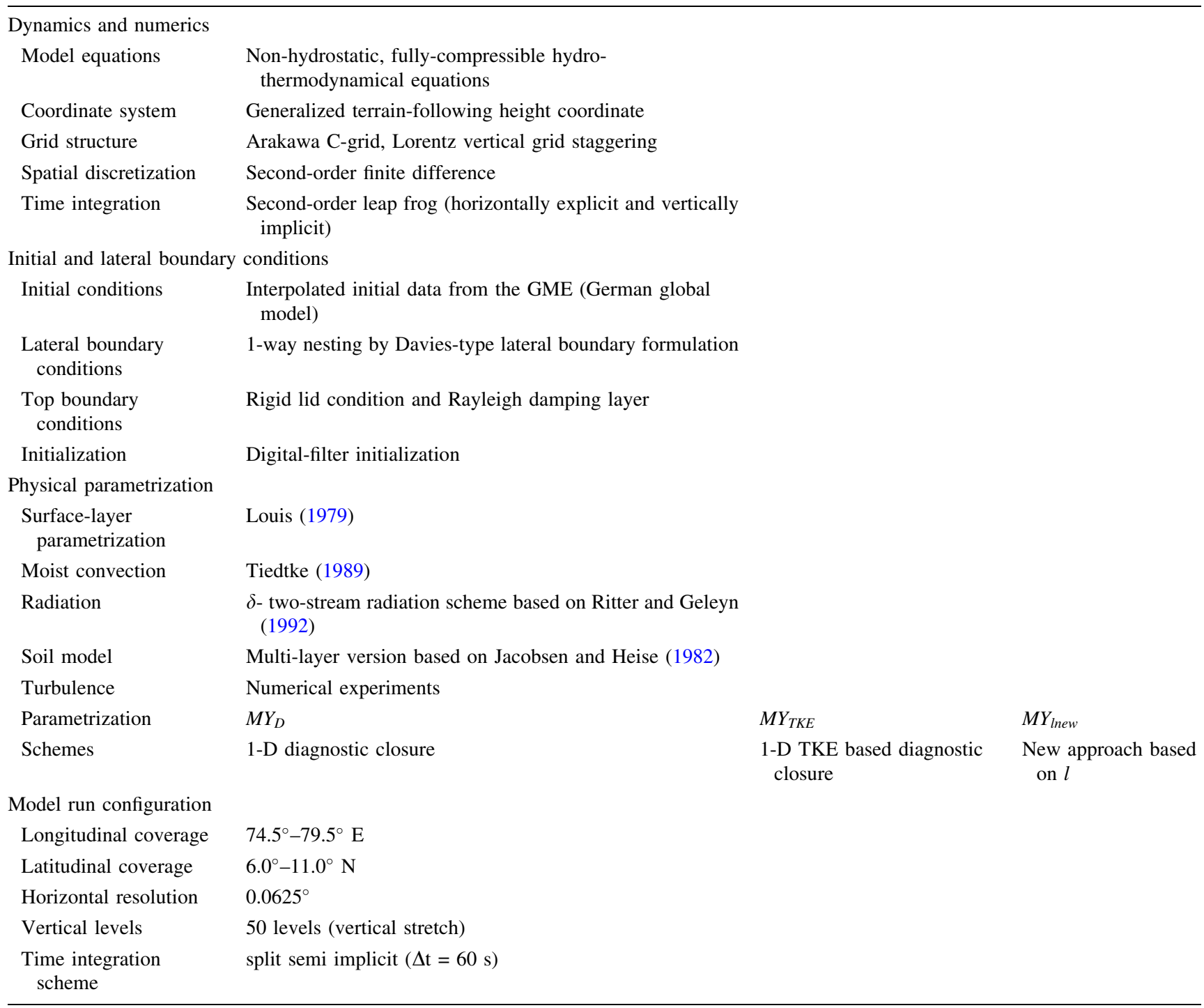

respectively in Fig. 2. The grid point closest to Thiruvananthapuram in the COSMO model domain is located at an elevation of about $20 \mathrm{~m}$ and the surface roughness length corresponding to this grid is roughly $0.42 \mathrm{~m}$ (Fig. 2).

\section{Behaviour of eddy diffusivity coefficients}

The performance of any ABL parametrization scheme based on K-closure, largely relies on the way the eddy diffusivity coefficients represent the turbulent structure within the boundary layer. Generally, the eddy diffusivity coefficients are prescribed to increase with the intensity of the turbulence, which vary with height above the ground, mean wind shear and surface heating (Wallace and Hobbs 2006). The eddy diffusivity coefficients can change in time and space depending upon the atmospheric conditions and stability. These coefficients are usually estimated as a combination of dimensional considerations and empirical measurements and can be assumed as a product of turbulent velocity scale and master length scale, in analogy with the way molecular mixing is related to the molecular velocities and mean free path. The vertical profiles of $K_{m}$ and $K_{h}$ are good representative of intensity of eddy diffusion and also indicate an altitude upto which the vertical turbulent mixing is dominated, thereby providing a rough measure on the ABL heights (Stull 1988; Garratt 1992). With a view to examining the differences in the structure of the eddy diffusivity coefficients for typical daytime and nocturnal conditions, we depict the vertical profiles of $K_{m}$ and $K_{h}$ for three different numerical experiments corresponding to 1430 and 0230 local time of 10 February 2011 in the top and bottom panels respectively in 


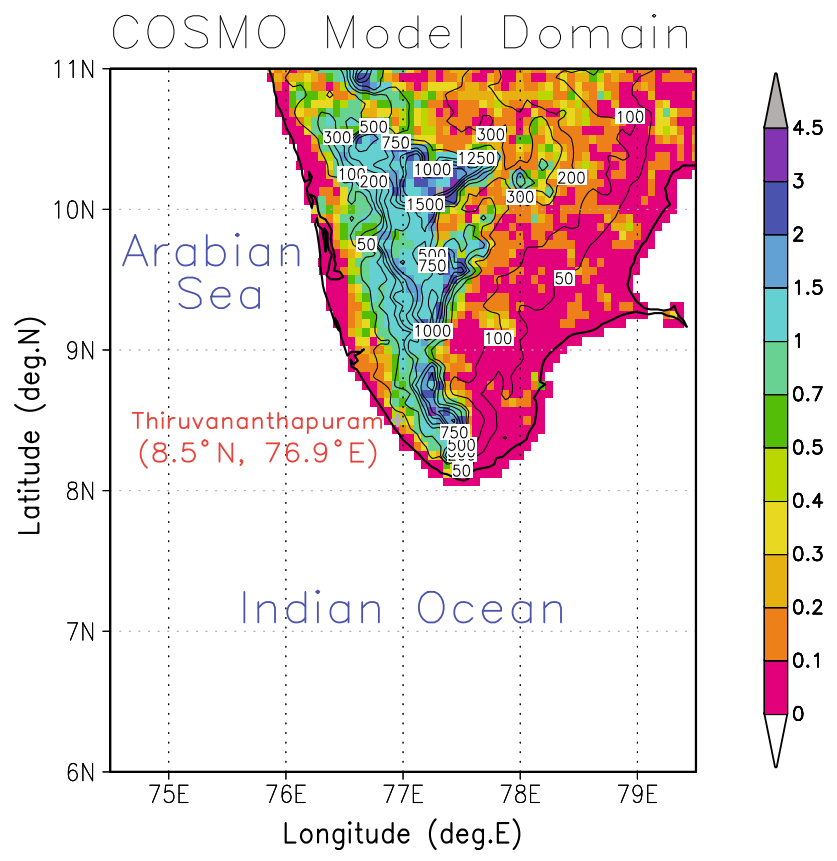

Fig. 2 Spatial heterogeneity in the terrain elevation (contour lines) and surface roughness length (shaded area) in metres over the study domain in the COSMO model

Fig. 3. The vertical profiles of $K_{m}$ and $K_{h}$ simulated through three different numerical experiments corresponding to daytime conditions differ in magnitudes, but the altitude corresponding to the peak value of these coefficients remains identical, as apparent from Fig. 3a and $b$. The introduction of stability corrected master length scale for daytime conditions in the $M Y_{\text {lnew }}$ parametrization approach leads to a significant increase in the magnitudes of $K_{m}$ and $K_{h}$ in comparison to the original magnitudes inferred from the $M Y_{D}$ scheme, in turn indicating the presence of an intense vertical mixing within the $\mathrm{ABL}$, primarily attributed to the improved definition of $l$ in the $M Y_{\text {lnew }}$ approach. While the vertical profile of $K_{m}$ for the daytime inferred from the $M Y_{\text {lnew }}$ and the $M Y_{T K E}$ experiments do not show any large differences, the peak magnitude of eddy diffusivity coefficient for heat shows a remarkable increase in the case of the $M Y_{\text {lnew }}$ experiment (Fig. 3a, b). Unlike for the daytime convective conditions, the vertical profiles of $K_{m}$ and $K_{h}$ corresponding to the nocturnal conditions for all the three experiments exhibit a stable behaviour of $\mathrm{ABL}$ with a very weak vertical mixing in the lower layers, as can be clearly seen through the low magnitudes of these coefficients $\left(\sim 1 \mathrm{~m}^{2} \mathrm{~s}^{-1}\right.$; Fig. 3c, d). In the case of the $M Y_{T K E}$ experiment for the nocturnal conditions, the magnitudes of $K_{m}$ and $K_{h}$ remain consistently close to unity for all the lower levels $(<1000 \mathrm{~m})$. From these variations in the vertical profiles of $K_{m}$ and $K_{h}$, it is evident that the magnitudes of these coefficients are sensitive to the choice of mathematical formulation for the master length scale, as well as on the parametrization approach itself.

\section{Impact of $K_{m}$ and $K_{h}$ profiles of the vertical structure of $\mathbf{A B L}$}

The eddy diffusivity coefficients directly influence the vertical diffusion of momentum, and scalar (heat and moisture) fluxes, and therefore play an important role in the simulation of vertical profiles of winds, temperature and water vapour in the ABL. Here, we investigate the impact of $K_{m}$ and $K_{h}$ profiles simulated through three distinct approaches on the vertical structure of ABL by comparing the model-simulated features with the concurrent in situ observations. Figure $4 \mathrm{a}-\mathrm{c}$ and $\mathrm{d}-\mathrm{f}$ depict the vertical profiles of $\theta$, wind speed (WS) and relative humidity $(R H)$ simulated through the COSMO model, together with the in situ observations, for 1430 (top panel) and 0230 local time (bottom panel) respectively on 10 February 2011. The balloon-borne in situ measurements of $\theta, W S$ and $R H$ corresponding to 1430 local time show a typical daytime boundary layer, though shallow in nature, extending from the surface to an altitude of about $250 \mathrm{~m}$ (Fig. 4a-c). The top of the ABL inferred from the peak value of $K_{m}$ and $K_{h}$ profiles (Fig. 3a, b) also indicates the presence of vertical turbulent mixing up to $300 \mathrm{~m}$. Though the simulated magnitudes of $\theta$ are $1-2^{\circ} \mathrm{C}$ cooler than the corresponding in situ observations, their vertical structure also reveals a shallow convective boundary layer. Simulation of relatively warmer potential temperatures through the $M Y_{\text {lnew }}$ scheme in comparison with the $M Y_{D}$ scheme is attributed to the redefined mathematical formulation of stability corrected $l$ adopted in the former scheme. During the daytime, the wind speed variations observed through in-situ measurements are mostly benign $\left(<4 \mathrm{~m} \mathrm{~s}^{-1}\right)$ within the ABL, and the lower atmosphere is mostly humid $(R H>60 \%)$. Qualitatively, the vertical profiles of wind speed simulated through all the three experiments appear in tune with the in situ observations, however the model could not reproduce the altitude corresponding to the peak winds very accurately (Fig. 4b). Among the three numerical experiments, the $M Y_{T K E}$ and $M Y_{\text {lnew }}$ schemes yield very similar features in the wind speed profiles, which is possibly due to the identical behaviour of $K_{m}$ profiles obtained through these set of simulations (Fig. 3a). The vertical profiles of water vapour simulated through three schemes show drier $\mathrm{ABL}$ as seen through the $R H$ variations, which are mostly confined to below $50 \%$ only, whereas the in situ observations indicate relatively humid weather (Fig. 4c). In the case of nocturnal ABL corresponding to 0230 local time, the vertical profiles of $\theta$ simulated from all the three numerical experiments reveal features pertinent to the 
Fig. 3 Vertical profiles of $\mathbf{a}, \mathbf{b}$ eddy diffusivity coefficients for momentum $\left(K_{m}\right)$ and heat $\left(K_{h}\right)$ simulated through three numerical experiments in the COSMO model for the daytime conditions (1430 local time) over Thiruvananthapuram on 10 February 2011, c, d same as $\mathbf{a}$ and $\mathbf{b}$, but for the nocturnal conditions (0230 local time) on 10 February 2011
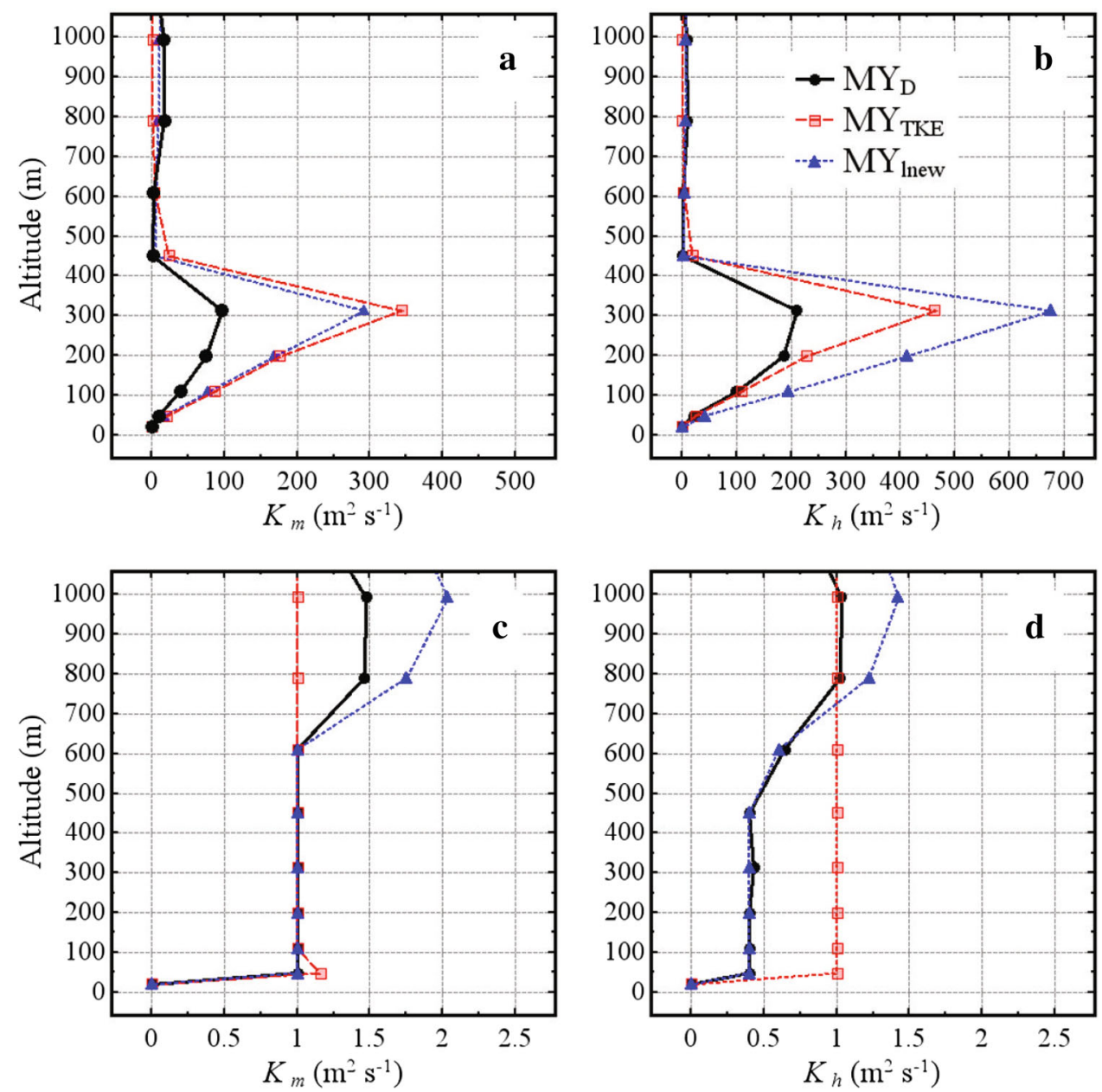

stable atmosphere, similar to that seen in the in situ observations (Fig. 4d). There are no major differences in the model-simulated ABL features of $W S$ and $R H$ profiles among the three schemes for the nocturnal conditions.

With a view to quantifying the errors and deviations in the model-simulated features of ABL with respect to the in situ observations, we have estimated the root-meansquare error (RMSE) in potential temperature $\left(\theta_{R M S E}\right)$, wind speed $\left(W S_{R M S E}\right)$ and relative humidity $\left(R H_{R M S E}\right)$ corresponding to 1430 and 0230 local time for the whole database, and are depicted in the top and bottom panel respectively of Fig. 5a-f. While all the numerical experiments reproduced the turbulent mixing within the ABL and associated vertical structure reasonably well in comparison with the concurrent observations, the absolute magnitudes of $\theta$ obtained from the model simulations differ by $1-3{ }^{\circ} \mathrm{C}$, as evident from the $\theta_{R M S E}$ values shown in Fig. 5a and $\mathrm{d}$. The errors associated with the wind speed simulations for the daytime as well as for the nighttime conditions corresponding to the lower altitudes $(<600 \mathrm{~m})$ are small, with negligible differences among the three schemes, whereas for the higher altitudes $(>600 \mathrm{~m})$, the $W S_{R M S E}$ magnitudes are relatively higher (Fig. 5b,e). For these altitudinal regions, the $M Y_{D}$ scheme yields relatively large errors, which are successively minimized in the $M Y_{\text {lnew }}$ scheme through the inclusion of a new $l$ formulation. The magnitudes of $R H_{R M S E}$ are relatively higher for the nocturnal conditions in comparison with the daytime simulations (Fig. 5c,f). A comparison of the model-simulated features in the ABL from three schemes reveals identical performance in the lower altitudes during the nocturnal conditions, in turn indicating a less role of the $\mathrm{ABL}$ schemes in the simulation of basic meteorological parameters for the stable state of the atmosphere.

\section{Representation of the ABL thickness}

The performance of any ABL parametrization scheme is also linked with its ability in simulating the vertical thickness of the ABL and its diurnal variations to a larger accuracy over a given site. The height (or depth) of the ABL is one of the fundamental variables which determines several tropospheric processes critical to air pollution, such as distribution of aerosols, convection, cloud and fog 

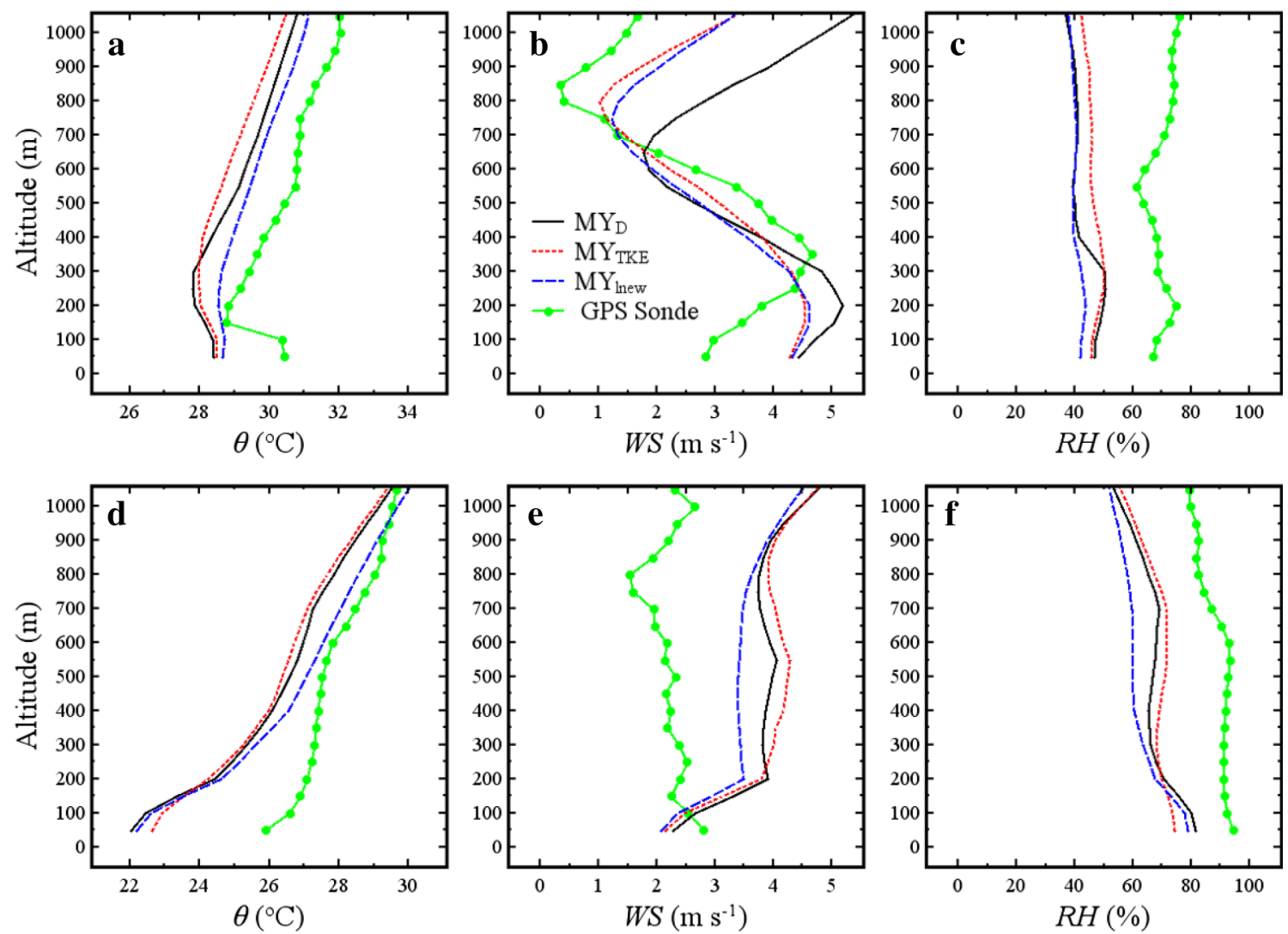

Fig. 4 Vertical profiles of a potential temperature $(\theta)$, b wind speed (WS), and $\mathbf{c}$ relative humidity $(R H)$ for the daytime conditions (1430 local time) on 10 February 2011, d-f same as a-c, but for the nocturnal conditions (0230 local time) on 10 February 2011

formation, and vertical extent of mixing and the level at which exchange with free atmosphere occurs (Bhumralkar 1976; Seibert et al. 2000; Medeiros et al. 2005; Seidel et al. 2010). In the atmospheric models, the ABL heights are used as a key length scale to determine turbulence mixing, vertical diffusion, convective transport, cloudaerosol entrainment, and atmospheric pollutant deposition (Deardorff 1972; Arakawa and Schubert 1974; Suarez et al. 1983; Wesely et al. 1985; Holtslag and Nieuwstadt 1986; Lin et al. 2008; Konor et al. 2009). Generally, the diagnosis of ABL heights in NWP models is accomplished through the usage of bulk Richardson number $\left(R i_{B}\right)$ profiles, where an altitude corresponding to the magnitudes of $R i_{B}$ exceeding a threshold value of 0.25 is identified as the top of the ABL (Sorensen 1998). In the present study also, the ABL heights simulated from the three numerical experiments are diagnosed through the $R i_{B}$ profiles. The mean diurnal evolution in the ABL heights corresponding to the three numerical experiments, together with the in situ observations are depicted in Fig. 6. Since, many of the observational studies advocate for the usage of virtual potential temperature $\left(\theta_{v}\right)$ and specific humidity profiles for the markation of the top of the ABL (Subrahamanyam et al. 2003, 2012), the ABL height variations inferred through $\theta_{v}$ and specific humidity profiles are also depicted in Fig. 6. Here, the vertical bars indicate the standard errors associated with the corresponding measurements for the entire database. Except for the noontime conditions (i.e., 1130 and 1430 local time), the ABL heights obtained from the model simulations (ranging from 98 to $877 \mathrm{~m}$ ) are well in tune with the corresponding observations (ranging from 100 to $616 \mathrm{~m}$ ), thereby reproducing the vertical mixing within the $\mathrm{ABL}$ in a realistic manner for all the three set of simulations. However, the ABL heights corresponding to 1130 and 1430 local time diagnosed through the model simulations are higher than the respective in situ measurements; though the deviations between the ABL heights obtained from the model simulations and observations through $R i_{B}$ method for 1130 local time are relatively smaller. For typical noontime conditions at 1430 local time, the ABL heights inferred from the $R i_{B}$ profiles, and $\theta_{v}$ and specific humidity profiles respectively are confined to below 600 $\mathrm{m}$ only, whereas the model simulations corresponding to the $M Y_{T K E}$ and $M Y_{D}$ schemes for these conditions indicate the presence of vertical mixing to an altitude of about 1700-1800 m respectively, reasonably higher than the in situ measurements. An inclusion of the stability 

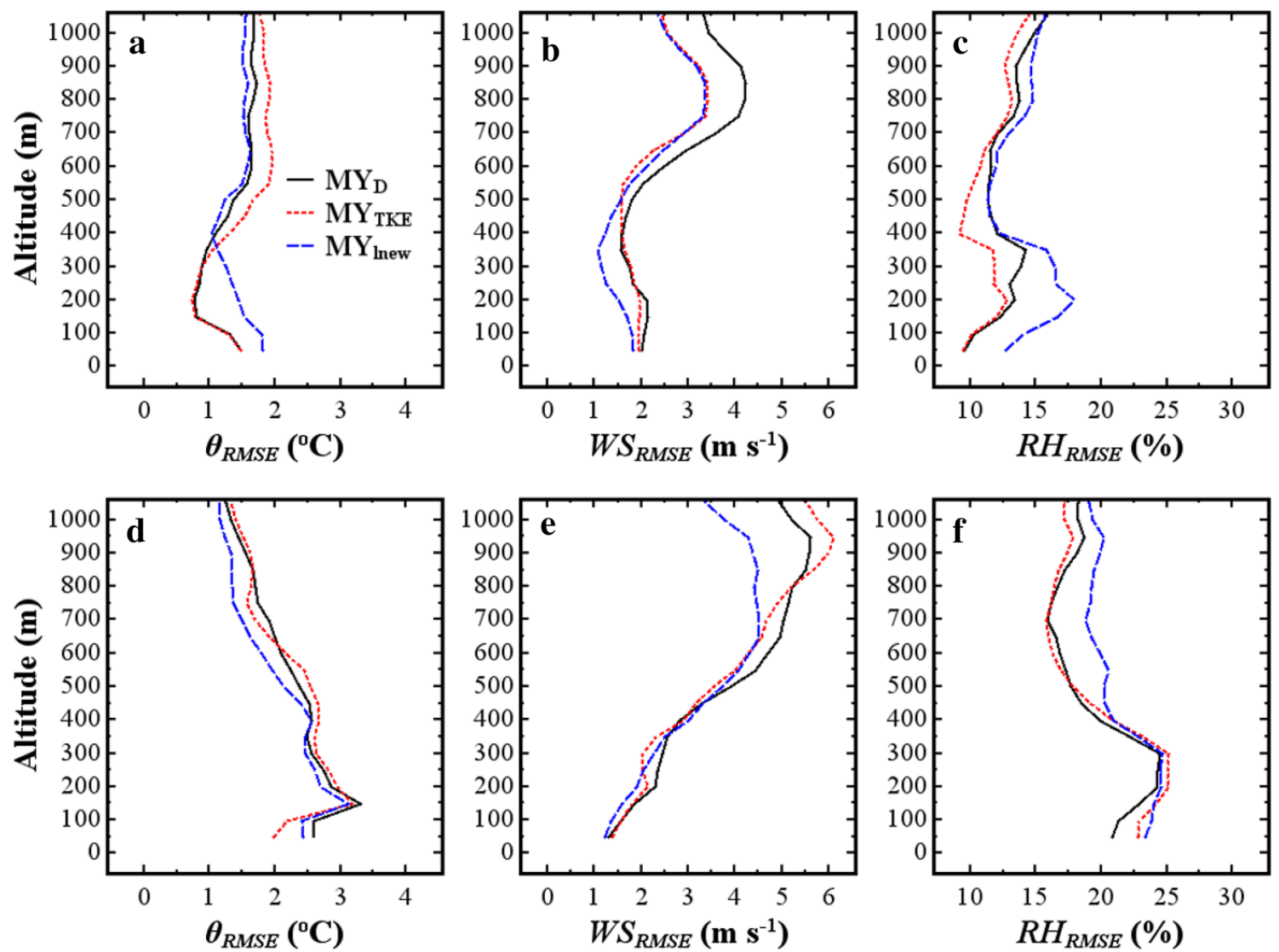

Fig. 5 Vertical profiles of root-mean-square errors in a potential temperature $\left(\theta_{R M S E}\right), \mathbf{b}$ wind speed $\left(W S_{R M S E}\right)$, and $\mathbf{c}$ relative humidity $\left(R H_{R M S E}\right)$ for the daytime conditions (1430 local time) for the entire

database, $\mathbf{d}-\mathbf{f}$ same as $\mathbf{a}-\mathbf{c}$, but for the nocturnal conditions (0230 local time) for the entire database
Fig. 6 The diurnal variations in the ABL heights inferred from the model simulations, together with the in situ observations

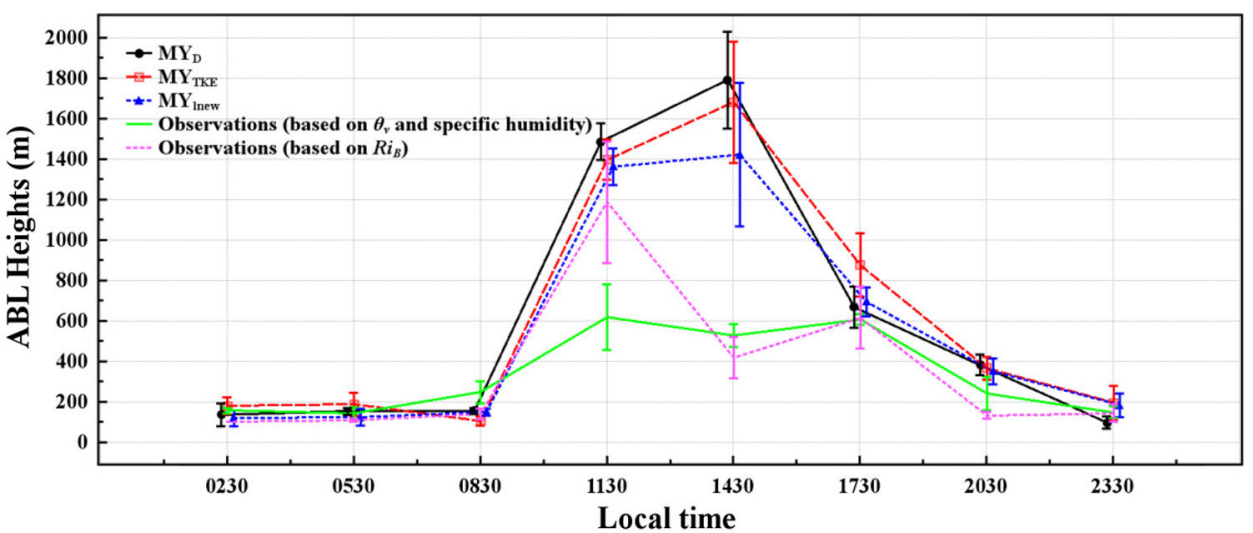

From the diurnal variations in the ABL heights inferred from the in situ measurements through two different approaches indicate considerable differences for the 1130 local time, which can be attributed to the plausible inhomogeneities in the ABL structure introduced by the onset of sea-breeze over the experimental site followed by the formation of a thermal internal boundary layer. Under the influence of sea-breeze circulation, the ABL is 
simultaneously affected with a humid airmass intruding from the oceanic regions and a relatively dry airmass prevailing over the experimental site. An interaction of two such different air masses leads to a significant inhomogeneity in the vertical structure of ABL during the onset phase of the sea-breeze, which generally occurs at about 1000 local time over Thiruvananthapuram in the month of February (Anurose et al. 2012). During such conditions, even though the atmospheric flow remains turbulent up to an altitude of about $1100 \mathrm{~m}$, the vertical mixing of water vapour is seen to be confined within $600 \mathrm{~m}$ only; thus the ABL heights inferred from $R i_{B}$ method, and $\theta_{v}$ and specific humidity profiles yield two different values. By the 1430 local time, Thiruvananthapuram experiences a wellevolved sea-breeze circulation and the ABL heights inferred from both the approaches yield shallow boundary layer confined within $550 \mathrm{~m}$ (Fig. 6). The model simulations with three distinct approaches of the ABL parametrization scheme did not predict a shallow boundary layer for the noontime conditions, probably due to the lesser sensitivity of the schemes to inhomogeneous conditions of the ABL actually prevailed over the site.

\section{Concluding remarks}

The present work evaluates three distinct $\mathrm{ABL}$ parametrization schemes based on the K-closure in the COSMO, a non-hydrostatic atmospheric model over Thiruvananthapuram. The COSMO model offers two options for the parametrization of boundary-layer processes, viz, (i) the 1-D diagnostic closure $\left(M Y_{D}\right)$ and (ii) the 1-D TKE-based diagnostic closure $\left(M Y_{T K E}\right)$. With a view to investigating the role of master length scale in the these schemes, a new stability corrected definition for $l$ is adopted and a third distinct parametrization scheme $\left(M Y_{\text {lnew }}\right)$ is devised and implemented in the model. The model simulations with these three configurations are carried out for a total of nine days and the model-simulated ABL features are compared with the concurrent in situ observations. Results obtained from this evaluation study highlight the importance and sensitivity of $l$ in the vertical turbulent diffusion and in the estimation of eddy diffusivity coefficients. The discrepancies between the model-simulated ABL heights and the observations for the daytime conditions can be attributed to the inhomogeneous behaviour of the $\mathrm{ABL}$, which require proper attention in future studies on theoretical formulation of the boundary-layer parametrization. The main results obtained from this research work are summarized below:

1. The magnitudes of eddy diffusivity coefficients $\left(K_{m}\right.$ and $K_{h}$ ) simulated from the three approaches of ABL parametrization scheme for the daytime conditions differ in the magnitudes, but they attain a peak at similar altitudes. There are no major differences in the behaviour of $K_{m}$ and $K_{h}$ profiles for the nocturnal conditions.

2. An introduction of the stability corrected master length scale in the $M Y_{\text {lnew }}$ experiment resulted in improved performance of the wind speed simulations in comparison with the $M Y_{D}$ experiment, particularly for the high altitudes. However, the $M Y_{\text {lnew }}$ simulations exhibit poor performance in the simulations of scalar quantities, such as $\theta_{v}$ and $R H$ in the lower model levels.

3. Except for the local noontime conditions, the three set of numerical experiments yield ABL heights close to the observations; however the model simulations are found to be less sensitive to the the inhomogeneous conditions of the ABL during the noontime, as they are not able to reproduce the observed shallow boundary layers.

4. Among the three set of model simulations, the $M Y_{\text {lnew }}$ experiment leads to constrained vertical mixing and relatively shallow $\mathrm{ABL}$ for the noontime conditions.

Acknowledgments We express our sincere gratitude to Dr. Detlev Majewski and his colleagues from the Deutscher Wetterdienst, Germany for their support in setting up of the COSMO model and for providing the initial and lateral boundary conditions for the study period. One of the authors Ms. TJA is thankful to the Indian Space Research Organization for sponsoring fellowship for her Ph.D. research work. We also thank Dr. Radhika Ramachandran for her valuable comments and support for carrying out this piece of research work. The observational data for the present study is collected as a part of the Tropical Tropopause Dynamics experiment under the CAWSES-India program and is duly acknowledged.

\section{References}

Anurose TJ, Subrahamanyam DB, Dutt CBS, Kumar NVPK, John SR, Nair SK, Santosh M, Mohan M, Kunhikrishnan PK, Sijikumar S, Prijith SS (2012) Vertical structure of sea-breeze circulation over thumba $(8.5 \mathrm{~N}, 76.9 \mathrm{E}$, India) in the winter months and a case study during W-ICARB field experiment. Meteorol Atmos Phys 115(3-4):113-121

Arakawa A, Schubert WH (1974) Interaction of a cumulus cloud ensemble with the large-scale environment, part I. J Atmos Sci 31:674-701

Arya SP (2001) Introduction to micrometeorology. Academic Press, San Diego

Baldauf M, Seifert A, Forstner J, Majewski D, Raschendorfer M, Reinhardt T (2011) Operational convective-scale numerical weather prediction with the COSMO model: description and sensitivities. Mon Weather Rev 139:3887-3905. doi:10.1175/ MWR-D-10-05013.1

Basu S, Raman S, Mohanty UC, Rajagopal EN (1998) Impact of boundary-layer parameterisation schemes on the prediction of the Asian summer monsoon. Bound Layer Meteorol 86:469-485 
Basu S, Raman S, Mohanty UC, Rajagopal EN (1999) Influence of the planetary boundary layer physics on medium-range prediction of monsoon over India. Pure Appl Geophys 155:35-55

Bhumralkar CM (1976) Parameterization of the planetary boundary layer in atmospheric general circulation models. Rev Geophys $14: 215-226$

Blackadar A (1962) The vertical distribution of wind and turbulent exchange in neutral atmosphere. J Geophys Res 67:3095-3102

Buzzi M (2008) Challenges in operational numerical weather prediction at high resolution in complex terrain. In: Dissertation ETH No. 17714, Verffentlichung MeteoSchweiz No. 80, Swiss Fedral Institute of Technology, Zurich

Deardorff JW (1972) Parameterization of the planetary boundary layer for use in general circulation models. Mon Weather Rev 100:93-106

Doms G, Forstner J, Heise E, Herzog HJ, Mironov D, Raschendorfer T, Reinhardt T, Ritter B, Schrodin, J-P, Schulz, Vogel G (2011) A description of the non-hydrostatic regional COSMO model. Part-II: Physical parameterization Deutscher Wetterdienst, Offenbach

Garratt JR (1992) The atmospheric boundary layer. Cambridge University Press, Cambridge

Holton JR (2004) An introduction to dynamic meteorology. Elsevier Academic Press, San Diego

Holtslag AAM, Nieuwstadt FTM (1986) Scaling the atmospheric boundary layer. Bound Layer Meteorol 36:201-209

Hu XM, Nielsen-Gammon JW, Zhang F (2010) Evaluation of three planetary boundary layer schemes in the WRF model. J Appl Meteor Clim 49:1831-1844. doi:10.1175/2010JAMC2432.1

Jacobsen I, Heise E (1982) A new economic method for the computation of the surface temperature in numerical models. Control Atmos Phys 55:128-141

Konor CS, Boezio GC, Mechoso CR, Arakawa A (2009) Parameterization of PBL processes in an atmospheric general circulation model: description and preliminary assessment. Mon Weather Rev 137:1061-1082

Lee TY, Hong SY (2005) A new terrain-following vertical coordinate formulation for atmospheric prediction models. Bull Am Meteorol Soc 86:1615-1618. doi:10.1175/BAMS-86-11-1615

Lenderink G, Holtslag AAM (2004) An updated length-scale formulation for turbulent mixing in clear and cloudy boundary layers. Q J R Meteorol Soc 130(604):3405-3427

Lin JT, Youn D, Liang XZ, Wuebbles DJ (2008) Global model simulation of summertime U.S. ozone diurnal cycle and its sensitivity to PBL mixing, spatial resolution, and emissions. Atmos Environ 42:8470-8483

Louis J (1979) A parametric model of vertical eddy fluxes in the atmosphere. Bound Layer Meteorol 17:187-202

Medeiros B, Hall A, Stevens B (2005) What controls the climatological depth of the PBL? J Clim 18:2877-2892. doi:10.1175/ JCLI3417

Mellor GL, Yamada T (1974) A hierarchy of turbulence closure models for planetary boundary layers. J Atmos Sci 31:1791-1806

Nakanishi M (2001) Improvement of the melloryamada turbulence closure model based on large-eddy simulation data. Bound Layer Meteorol 99:349-378

Nielsen-Gammon JW, Hu XM, Zhang F, Pleim JE (2010) Evaluation of planetary boundary layer scheme sensitivities for the purpose of parameter estimation. Mon Weather Rev 138:3400-3417. doi:10.1175/2010mwr3292.1

Pielke RA (2002) Mesoscale meteorological modeling. Academic Press, Orlando

Pleim JE (2007a) A combined local and nonlocal closure model for the atmospheric boundary layer. Part I: Model description and testing. J Appl Meteorol Climatol 46:1383-1395
Pleim JE (2007b) A combined local and nonlocal closure model for the atmospheric boundary layer. Part II: Application and evaluation in a mesoscale meteorological model. J Appl Meteorol Climatol 46:1396-1409

Raupach MR, Thom AS (1981) Turbulence in and above plant canopies. Ann Rev Fluid Mech 13:97-129

Ritter B, Geleyn JF (1992) A comprehensive radiation scheme for numerical weather prediction models with potential applications in climate simulations. Mon Weather Rev 120:303-325

Schar C, Leuenberger D, Fuhrer O, DL, Girard C, (2002) A new terrain-following vertical coordinate formulation for atmospheric prediction models. Mon Weather Rev 130:2459-2480. doi:10. 1175/MWR-D-10-05013.1

Seibert P, Beyrich F, Gryning SE, Joffre S, Rasmussen A, Tercier P (2000) Review and intercomparison of operational methods for the determination of the mixing height. Atmos Environ 34:1001-1027

Seidel DJ, Ao CO, Li K (2010) Estimating climatological planetary boundary layer heights from radiosonde observations: comparison of methods and uncertainty analysis. J Geophys Res 115(D16,113):1-15. doi:10.1029/2009JD013680

Shah S, Rao BM, Kumar P, Pal PK (2010) Verification of cloud cover forecast with insat observation over Western India. J Earth Syst Sci 119(6):775-781

Someria G, Deardoff JW (1976) Subgrid-scale condensation in models of non-precipitating clouds. J Atmos Sci 34:344-355

Sorensen JH (1998) Sensitivity of the derma long-range Gaussian dispersion model to meteorological input and diffusion parameters. Atmos Environ 32:4195-4206

Stensrud DJ (2007) Parameterization schemes: keys to understanding numerical weather prediction models. Cambridge University Press, Cambridge

Steppeler J, Doms G, Schattler U, Bitzer H, Gassmann A, Darmrath U, Gregoric G (2003) Meso-gamma scale forecast using the nonhydrostatic model LM. Meteorol Atmos Phys 82:75-96

Stull RB (1988) An introduction to boundary layer meteorology, vol 17. Kluwer Academic Publishers, The Netherlands

Suarez MJ, Arakawa A, Randall DA (1983) The parameterization of the planetary boundary layer in the UCLA general circulation model: formulation and results. Mon Weather Rev 111:2224-2243

Subrahamanyam DB, Radhika R, SenGupta K, Mandal TK (2003) Variability of mixed layer heights over the Indian Ocean and Central Arabian Sea during INDOEX, IFP-99. Bound Layer Meteorol 107:683-695

Subrahamanyam DB, Anurose T, Mohan M, Santosh M, Kiran Kumar N, Sijikumar S (2012) Impact of annular solar eclipse of 15 January 2010 on the atmospheric boundary layer characteristics over Thumba: a case study. Pure Appl Geophys 169(4):741-753. doi:10.1007/s00024-011-0336-9

Suelj K, Sood A (2010) Improving the Mellor Yamada Janjic parameterization for wind conditions in the marine planetary boundary layer. Bound Layer Meteorol 136:301-324

Teixeira J, Cheinet S (2004) A simple mixing length formulation for the eddy-diffusivity parameterization of dry convection. Bound Layer Meteorol 110(3):435-453

Teixeira J, Stevens B, Bretherton CS, Cederwall R, Doyle JD, Golaz JC, Holtslag AAM, Klein SA, Lundquist JK, Randall DA, Siebesma AP, Soares PMM (2003) Parameterization of the atmospheric boundary layer: a view from just above the inversion. Bull Am Meteorol Soc 89(4):453-458. doi:10.1175/ BAMS-89-4-453

Tiedtke M (1989) A comprehensive mass flux scheme for cumulus parameterization in large scale models. Mon Weather Rev 117:1779-1800 
Troen I, Mahrt L (1986) A simple model of the atmospheric boundary layer: sensitivity to surface evaporation. Bound Layer Meteorol 37:129-148

Wallace JM, Hobbs PV (2006) Atmospheric science an introductory survey, 2nd edn. In: International geophysics series, vol 92. Acadamic Press, New York

Wesely ML, Cook DR, Hart RL, Speer RE (1985) Measurements and parameterization of particulate sulfur dry deposition over grass. J Geophys Res 90(D1):2131-2143
Yamartino RJ, Wiegand G (1986) Development and evaluation of simple models for the flow, turbulence and pollution concentration fields within an urban street canyon. Atmos Environ 20:2137-2156 